\title{
Prevalence of biochemical hypoglycaemia in everyday practice
}

\author{
Lina Zabuliene $e^{1,2,5}$, Birute Pauliukiené2 ${ }^{2}$ Airida Audrone Bagdziuniene', \\ Jurgita Urboniene ${ }^{4}$

\section{'Clinics of Rheumatology Traumatology-C} \\ Clinics of Rheumatology, Traumatology-Orthopaedics
outpatient clinic, Vilnius, Lithuania; ${ }^{3}$ Centre of Endo \\ Tuberculosis Hospital, Vilnius University hospital Saninology, Vilni
}

\section{INTRODUCTION}

Oral glucose tolerance test (OGTT) is the main tool in population based screening for type $2 \mathrm{di}-$ abetes mellitus. Sometimes OGTT results show asymptomatic lowering of post-load blood glucose. Post-load plasma glucose (2hPG) level $\leq 3.9$ $\mathrm{mmol} / \mathrm{l}(70 \mathrm{mg} / \mathrm{dl})$ shows biochemical hypoglycaemia. Biochemical hypoglycaemia might be observed among individuals with abnormal glucose tolerance and in a healthy population. Recent studies have reported different prevalence of biochemical hypoglycaemia: idiopathic reactive hypoglycaemia was found in $12.4 \%$ of elderly people [1], in $23 \%$ of healthy Asian Indians [2], in $50 \%$ of lean young women with polycystic ovary syndrome [3] and in 5.5\% of UK multi-ethnic population [4]. Wide variety in the rate of biochemical hypoglycaemia can be explained by different post-load plasma glucose levels selected to define biochemical hypoglycaemia and different populations studied. Biochemical hypoglycaemia is associated with younger age, white European ethnicity. Recent studies have showed that biochemical hypoglycaemia during an OGTT in the absence of diabetes or impaired glucose regulation is not associated with insulin resistance, but instead appeared to be associated with more favourable glycaemic and metabolic risk profiles namely lower body mass index, lower body fat percentage, higher HDL cholesterol, lower triglycerides, higher insulin sensitivity, lower fasting glucose and $\mathrm{HbA} 1 \mathrm{C}$ than normal glucose tolerance and impaired glucose regulation [2,4]. According to data, clinicians may not need to intervene due to biochemical hypoglycaemia on a 2-h OGTT [4].

\section{OBJECTIVE}

The objective of the investigation was to assess a prevalence of biochemical hypoglycaemia during OGTT in routine outpatient practice.

\section{MATERIAL AND METHODS}

We conducted an audit of $75 \mathrm{~g}$ standardized OGTT performed at Vilnius Antakalnio outpatient clinic from 03Jan2011 to 15Dec2014 and analysed data of 5575 adult patients. We applied 2006 WHO criteria for impaired fasting glucose (IFG), impaired glucose tolerance (IGT) and diabetes. Patients with biochemical hypoglycaemia during OGTT, and with normal glucose tolerance (NGT) or IFG were compared using Student t-test. The significance level chosen to test statistical hypotheses was 0.05 .

\section{RESULTS}

Mean patients' age was $53.64 \pm 15.59$ years (36.4\% male and $63.6 \%$ female). Mean FPG was $5.87 \pm 0.65 \mathrm{mmol} / \mathrm{l}$, mean $2 \mathrm{hPG}$ was $6.20 \pm 2.25 \mathrm{mmol} / \mathrm{l}$. OGTT detected IFG in 1518 (27.2\%), IGT in 778 (14.0\%), diabetes in 286 (5.1\%) patients. NGT was found in 2993 patients.

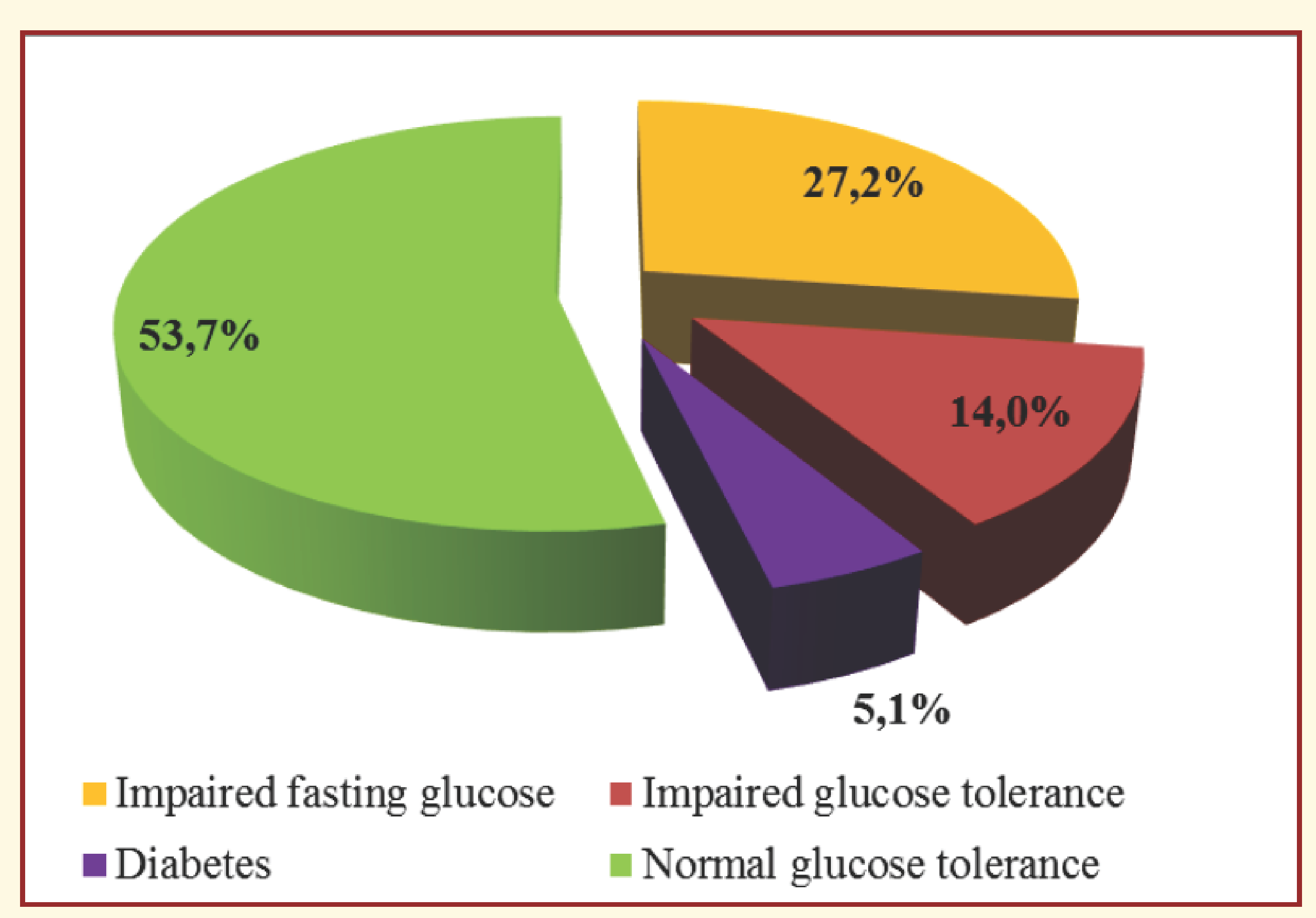

Figure 1. Distribution of patients by OGTT results

Total 760 patients (13.6\%) have had biochemical hypoglycaemia: 547 (18.3\%) patients with NGT and 213 (14.0\%) patients with IFG.
Table 1. Comparison of NGT patients' with and without biochemical hypoglycaemia

\begin{tabular}{|l|c|c|c|}
\hline Variable & $\begin{array}{c}\text { Biochemical hypoglycaemia, } \\
\mathrm{N}=547\end{array}$ & $\begin{array}{c}\text { Without biochemical } \\
\text { hypoglycaemia, } \mathrm{N}=2446\end{array}$ & $\mathrm{p}$ \\
\hline Age, years & $45.70 \pm 14.32$ & $50.72 \pm 16.12$ & $<0.0001$ \\
\hline FPG, $\mathrm{mmol} / \mathrm{l}$ & $5.38 \pm 0.45$ & $5.45 \pm 0.42$ & 0.001 \\
\hline 2hPG, mmol/I & $3.40 \pm 0.47$ & $5.64 \pm 0.98$ & $<0.0001$ \\
\hline Male/female, $\%$ & $24.4 / 15.5$ & $75.6 / 84.5$ & $<0.0001$ \\
\hline
\end{tabular}

Within NGT group patients having biochemical hypoglycaemia were younger by 5.02 years $(p<0.0001)$ and had lower level of FPG by $0.07 \mathrm{mmol} / \mathrm{l}(p=0.001)$ than those who didn't present biochemical hypoglycaemia. Males experienced biochemical hypoglycaemia more frequently than women $(24.4 \%$ vs $15.5 \%$, p $<0.0001)$.

Table 1. Comparison of IFG patients' with and without biochemical hypoglycaemia

\begin{tabular}{|l|c|c|c|}
\hline \multicolumn{1}{|c|}{ Variable } & $\begin{array}{c}\text { Biochemical hypoglycaemia, } \\
\mathrm{N}=213\end{array}$ & $\begin{array}{c}\text { Without biochemical hypoglycaemia, } \\
\mathrm{N}=1305\end{array}$ & $\mathrm{p}$ \\
\hline Age, years & $52.83 \pm 12.01$ & $56.44 \pm 13.42$ & $<0.0001$ \\
\hline FPG, $\mathrm{mmol} / \mathrm{l}$ & $6.41 \pm 0.24$ & $6.50 \pm 0.31$ & $<0.0001$ \\
\hline 2hPG, mmol/l & $3.46 \pm 0.38$ & $5.88 \pm 1.05$ & $<0.0001$ \\
\hline Male/female, \% & $20.0 / 9.0$ & $80.0 / 91.0$ & $<0.0001$ \\
\hline
\end{tabular}

Within IFG group patients with biochemical hypoglycaemia were younger by 3.61 years $(p<0.0001)$ and had lower level of FPG by $0.09 \mathrm{mmol} / \mathrm{l}(\mathrm{p}<0.0001)$ than those who didn't present biochemical hypoglycaemia. Males experienced biochemical hypoglycaemia more frequently than women $(20.0 \%$ vs $9.0 \%, p<0.0001)$

\section{CONCLUSION}

Prevalence of biochemical hypoglycaemia is about $14 \%$ in routine outpatient practice. Biochemical hypoglycaemia is associated with younger age, male gender and lower fasting plasma glucose level.

REFERENCES

Sorensen M, Johansen OE. Idiopathic reactive hypoglycaemia - prevalence and effect of fibre on glucose excursions. Scand $J$ Clin Lab Invest 2010; 70(6):385-91. Vasan SK, Ramachandran $\mathrm{P}$, Mathew M, Natraj $\mathrm{C}$, Antonisamy B, Thomas $\mathrm{N}$. Post-absorptive
glucose lowering in normal healthy individuals: an epidemiological observation. Diabetes Res Clin Pract 2014; $104(1):$ :5-7.

Altuntas $Y$, Bilir $M$, Ucak S, Gundogdu S. Reactive hypoglycemia in lean young women with PCOS and correlations with insulin sensitivity and with beta cell function. Eur $J$ Obstet Gynecol eprod Biol 2005; 119(2): 198-205.

Parekh S, Bodicoat DH, Brady E, Webb D, Mani H, Mostafa S, et al. Clinical characteristics of people experiencing biochemical hypoglycaemia during an oral glucose tolerance test: cross-sectio
analyses from a UK multi-ethnic population. Diabetes Res Clin Pract 2014; 104(3):427-34. $18 \mathrm{th}$ European Congress of Endocrinology, 28-31 May 2016, Munich, Germany 